\title{
Complete Urethral Duplicity: A Rare Cause of Urinary Incontinence, New Type According to Effman's Classification
}

\author{
Kimassoum Rimtebaye1, Franklin Danki Sillong2, Arya Zarif Agah Tashkand1, \\ Mignagnal Kaboro', Lamine Niang 3 , Serigne Magueye Gueye ${ }^{3}$ \\ ${ }^{1}$ Hôpital Général de Référence Nationale (HGRN) de N’Djaména, N'Djaména, Tchad \\ ${ }^{2}$ Hôpital Protestant de N'Gaoundéré, N'Gaoundéré, Cameroun \\ ${ }^{3}$ Hôpital Général de Grand Yoff (HOGGY) de Dakar, Dakar, Senegal \\ Email: melinarim@yahoo.fr
}

Received 7 September 2015; accepted 18 October 2015; published 21 October 2015

Copyright (C) 2015 by authors and Scientific Research Publishing Inc.

This work is licensed under the Creative Commons Attribution International License (CC BY). http://creativecommons.org/licenses/by/4.0/

(c) (7) Open Access

\section{Abstract}

Aim: To describe the clinical, anatomical, therapeutic aspects and propose a diagram of a new type of a complete urethral duplicity in classification of Effman. Material and Methods: This was a case report of a 14-year-old patient who suffered from birth of incontinence occurring while sitting with concept of preservation of normal urination. The patient was carrying two urethral meatus, one continent and the other incontinent. The two urethral meatus were easy to catheterize. The imagery was non-contributory. Resection of accessory urethra helped to make the patient continent. Informed consent was obtained from the patient's parents for the surgical management, the anonymous use of record and photographs for scientific aims. Results: The diagnosis of urethral duplicity was retained. An explanatory approach is reported, a new scheme is proposed to improve the classification of Effman. Conclusion: The urethral duplicity is a rare urogenital abnormality whose etiology and pathophysiology are not fully understood and has not finished delivering the secret of his classification.

\section{Keywords}

Urethral Duplication, Epispadias, Penis Kinking, Notochord, Sphincter

\section{Introduction}

Urethral duplicity (UD) is a rare congenital abnormality, preferentially affecting the male fetus [1]-[6]. It can be 
complete or incomplete, whether or not associated with other urogenital abnormalities such: hypospadias, epispadias, bladderexstrophy. Two types of classification are often adopted: Classification of Effman [7] is the most used, followed by the classification of Willams [8]. The literature reports 200 - 500 cases published until today. UD may be symptomatic or asymptomatic. When symptomatic, events are many and varied: recurrent urinary tract infections, dysuria type split urinary stream, urinary incontinence. Diagnosis is based on imaging namely retrograde cystourethrography (RCU).

The pathophysiology of UD is not yet well understood. Several theories attempt to explain without really convincing in the different anatomoclinical types. However, the authors agree to treat only the symptomatic UD. Surgical excision of the accessory urethra is possibly associated to the correction of associated malformations gives better results.

From a clinical case of special symptoms, the authors describe, with an illustrative scheme, a new type of UD in the classification of Effman and report their management.

\section{Observation}

Child XY, 14, in grade 5, referred from a health district of northern Chad at about $1300 \mathrm{~km}$ from the capital N'Djamena for management of urinary incontinence with conservation of normal urination evolving since birth. Informed consent was obtained from the patient's parents for the surgical management, the anonymous use of record and photographs for scientific aims.

On the interview, the patient reported the following: "I am in grade 5, I had to leave school because I constantly lost urine in the classroom. But I could also have normal urination. I was always wet with urine, which was upsetting my classmates who could not stand the stench left on me”.

Physical examination revealed: a healthy boy, circumcised male external genitalia, an epispadiac penis, two urethral meatus which one in a normal glandular position and the other in penile dorsal position in the distal third, extending by urethral gutter to the glans.

\section{Morphological Assessment}

The RCU (Figure 1) showed normal urethral opacity without stricture image and normal cystography without vesicouretral reflux (VUR).

The ultrasound pointed out a bladder in a state of repletion, acalculous, with regular contours.

We opted for a "double bladder catheterization for diagnostic purposes” (Figure 2). A first Foley’s catheter 16Fr

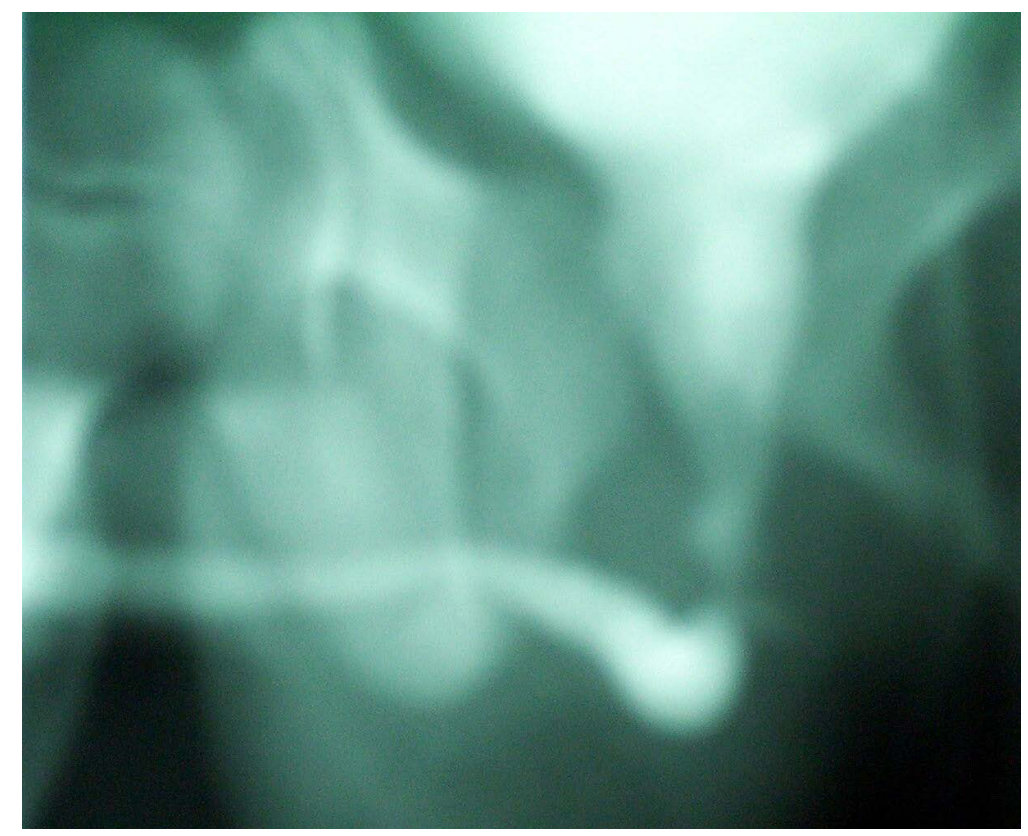

Figure 1. Normal RCU of the patient. 


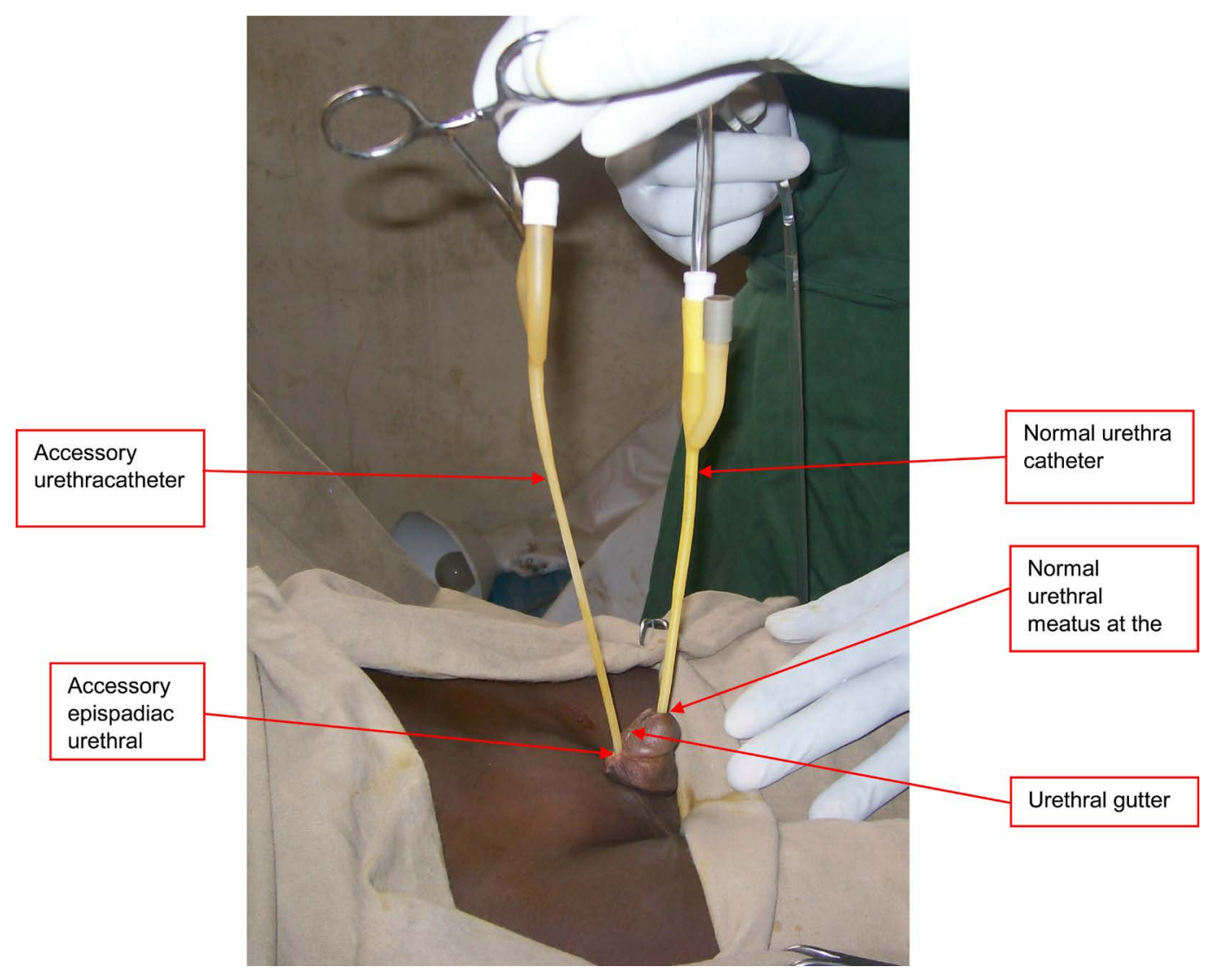

Figure 2. Double ureters; accessory epipadiac and normal glandular.

was readily posed by glandular meatus of the urethra in a normal prone position. The second catheter of the epispadiac meatus, also was easily placed. This second catheter was palpable throughout the prepubic and suprapubic route, under the skin, before losing in the hypogastrium. A second Foley's catheter 14Fr. was posed by the épispade meatus. The two catheters were fixed by inflating their balloon by 10 cc of saline. Unpublished observation: both catheters drain the urine of the same bladder. Moreover, saline introduced into the bladder through one catheter using a syringe of Guyon was drained automatically by the other catheter as shown in the dynamic picture (Figure 3). Therefore, the diagnosis of urethral duplicity was retained. It was a style not yet described in clinicopathologic classifications or Effman (Figure 4) or William. During the discussion, we will try an explanatory approach to the pathophysiology by using a scheme (Figure 5).

The decision of surgical resection of the accessory epispadiacurethra was taken and executed. The accessory urethra catheter was our guide for the incision and dissection. We dissected, ligated the proximal end of the urethra close to the top edge of the pubis and resected distal end thereof. Epispadias was corrected after the excision of the dorsal chordee of the penis (Figure 6). The histological analysis of the resected specimen confirmed a transitional epithelium. The postoperative aftermath was simple. The ablation of the catheter of glandular meatus was done at the 7th day. The patient was continent and had gone back to school in his region of origin, about $1300 \mathrm{~km}$ far from N'Djamena. Reached by phone, the patient's parents reassure the perfect urinary continence since 2008 .

\section{Discussion}

Urethral duplicity is a rare congenital malformation in urology, there are an estimated 200 - 500 publications to today. His discovery can be fortuitous when asymptomatic or be pointed out by a non pathognomonic urinary symptoms in a generally young patient. Multiple symptoms are reported by literature: recurrent urinary tract infections, total dysuria, split urinary stream, urinary incontinence, purulenturethral discharge from the meatus accessory. The UD is often associated with other malformations [9] that one should look for. It typically is: the 


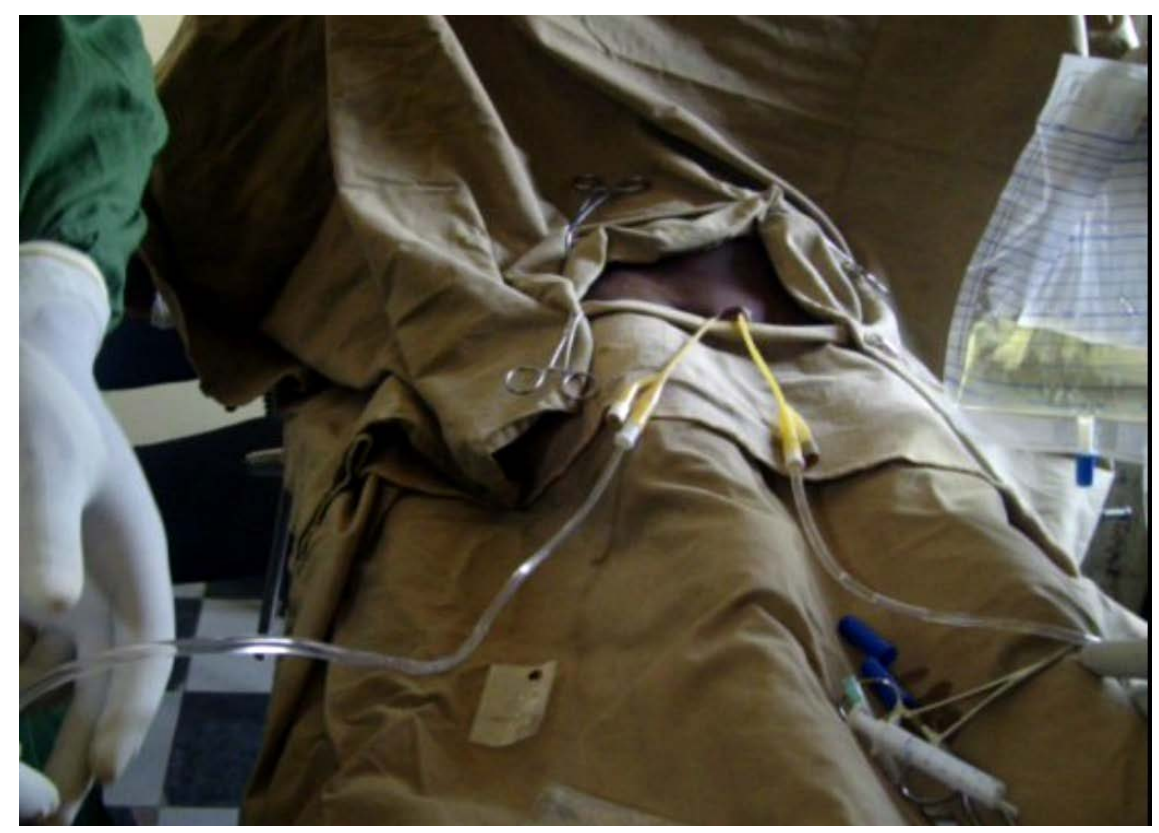

Figure 3. Bladder filling, draining the bladder content across the two probes.

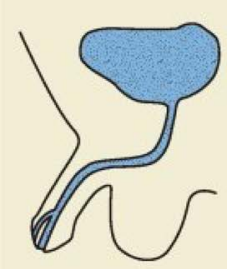

IA

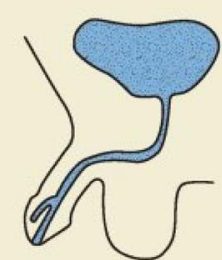

IB

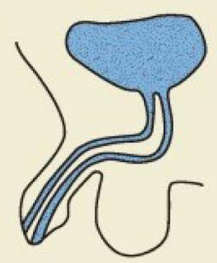

IIA 1

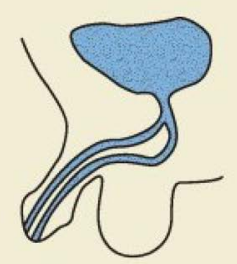

IIA 2

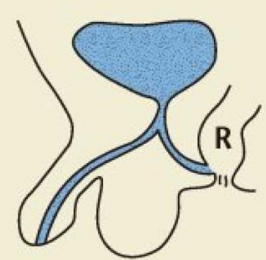

IIA 2 "Y type"

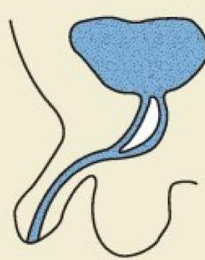

IIB

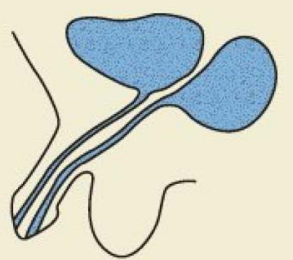

III

Figure 4. Classification of Effman.

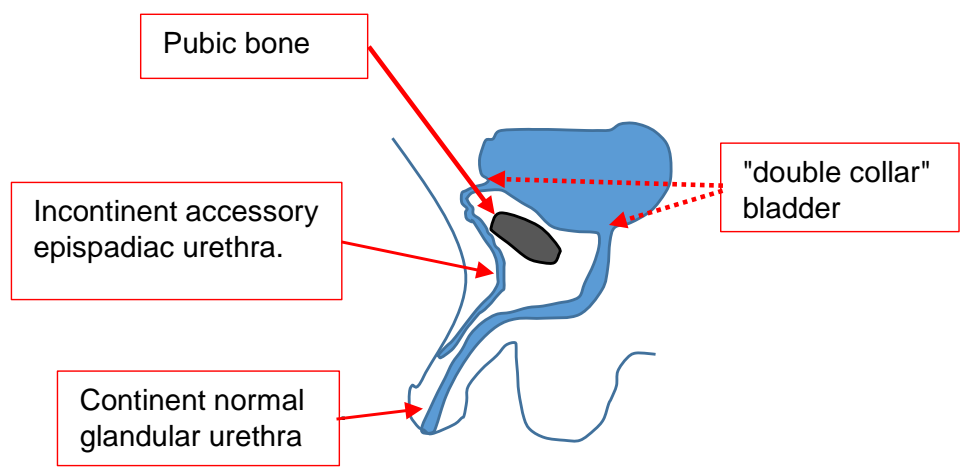

Figure 5. Scheme of a new case of urethral duplicity enlightening our observation. 


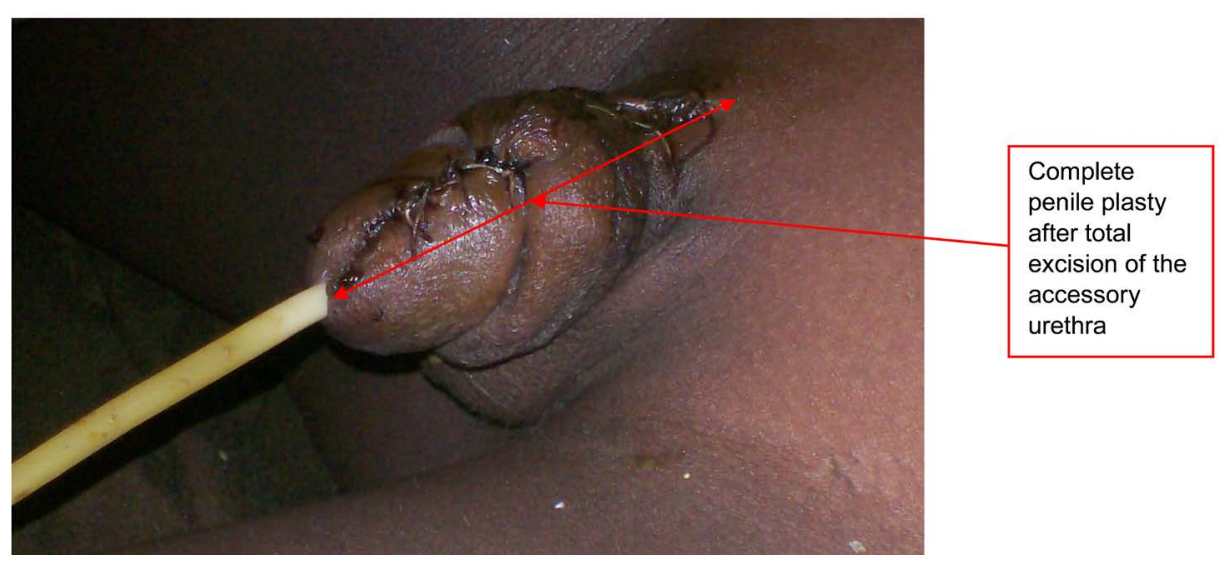

Figure 6. Post-operative appearance at D5.

kinking of the penis, the epispadias, hypospadias, phimosis, cryptorchidism, buried penis in the scrotum, penoscrotale transposition, bladder exstrophy, Prune Belly Syndrome, persistent peritoneal-vaginal canal. Several theories based on embryology are issued to try to explain without one of them takes the ascendancy over the others [10]-[12]. For Das and Brosman [11], to explain the embryological anomaly in organogenesis, the urogenital sinus opens at the urogenital diaphragm. An extension thereof facing the genital tubercle (urogenital blade) is absorbed to provide training to the urogenital gutter. The prostatic urethra and the membranous urethra are derived from the blade. Occlusion of the gutter, from back to front, allows the formation of the penile urethra marked externally by a median raphe. This is a Müllerian ducts regression default ending on the dorsal part of the urogenital sinus. Woodhouse and Williams [12] Merrot T [13] evoke meanwhile, an ischemic process during organogenesis. For others, it is a growth mismatch between the urogenital sinus and urethral entoblastique blade.

The most adopted classification of UD is that of Effman (Figure 4). We note that, from all types of UD described in the classification of Effman, the accessory urethra path never goes by both prepubic and suprapubic route as is the case with our patient (Figure 5). This particular path of accessory urethra lacks sphincter which causeshis incontinence. His stoma significantly higher on the anterior face of the bladder realizes incontinence that was done at full bladder while sitting on school benches where the bladder dome undergoes abdominal pelvic pressure. We will understand later the failure information provided by the RUC. However, glandular urethra with normal sphincter, realizes for the same patient, the concept of normal urination conservation. For the clinical case of our patient, we contribute by proposing to the classification of Effman a new type of total duplicity of the urethra: the kind IIA3 (Figure 5) alongside IIA1 and IIA2.

When the symptoms of UD is noisy, authors agree that treatment is surgical and consists to total resection of the accessory urethra [13] [14].

When a male child suffers from urinary incontinence with concept of preservation of normal urination, we have to think one of two possible anomalies. The total DU as described above or an ectopic anastomosis under the verumontanum of a ureter.

When the accessory urethra path goes by both prepubic and suprapubic route, it is automatically deprived of the external sphincter (striated) and internal sphincter (smooth) of the bladder neck. The lack of these two sphincters justifies the urinary incontinence.

\section{Conclusion}

Urethral duplicity is a rare congenital malformation often observed in male young adult. It can be associated with other genital malformations. The etiology and pathophysiology of the UD remain obscure to this day. The current classification of Effman needs to be improved by adding new types. Treatment of UD is surgical when the symptoms are noisy. This surgery involves the removal of the accessory urethra.

\section{References}

[1] Cicek, T., Kizilkan, Y., Çoban, G. and Kosan, M. (2015) Urethral Duplication. A Rare Cause of Recurrent Urinary Infection. Journal of the Pakistan Medical Association, 65, 90-92. 
[2] Verma, S., Gangkak, G., Yadav, S.S. and Tomar, V. (2015) Megalourethra with Y-Type Duplication of Urethra Presented as Perianal Fistula: A Rare Case Report. Case Reports in Urology, 2015, Article ID: 386131. http://dx.doi.org/10.1155/2015/386131

[3] Mori, K., Shin, T., Tobu, S., Noguchi, M., Sumino, Y., Sato, F. and Mimata, H. (2014) A Case of Urethral Duplication Arising from the Posterior Urethra to the Scrotum with Urinary Stone in a 6-Year-Old Male. Case Reports in Pediatrics, 2014, Article ID: 290623. http://dx.doi.org/10.1155/2014/290623

[4] Ramareddy, R.S., Alladi, A. and Siddappa, O.S. (2012) Urethral Duplication: Experience of Four Cases. Journal of Indian Association of Pediatric Surgeons, 17, 111-115. http://dx.doi.org/10.4103/0971-9261.98127

[5] Khandelwal, A., Gupta, S., Tiwari, R., Kumar, V. and Singh, M. (2012) Urethral Duplication: A Rare Cause of Urinary Incontinence in a Female Child. Central European Journal of Urology, 65, 90-91. http://dx.doi.org/10.5173/ceju.2012.02.art8

[6] Chu, A.J., Cho, J.Y., Kim, S.H. and Jun, J.K. (2010) Picture of the Month Prenatal Ultrasound Findings of Fetal Urethral Duplication. Ultrasound in Obstetrics and Gynecology, 36, 652-653. http://dx.doi.org/10.1002/uog.8832

[7] Effmann, E.L., Lebowitz, R.L. and Colodny, A.H. (1976) Duplication of the Urethra. Radiology, 119, 179-185. http://dx.doi.org/10.1148/119.1.179

[8] Williams, D.I. and Kenawi, M.M. (1975) Urethral Duplications in the Male. European Urology, 1, 209-215.

[9] Ben Nsir, R., Jouini, R., Maazoun, K., Helal, Y., Krichéne, I., Mekki, M. and Nouri, A. (2008) Epispadiac Urethral Duplication in Boys (L'urètre surnuméraire épispade chez le garçon). Progrès en urologie, 18, 570-574. http://dx.doi.org/10.1016/j.purol.2008.07.002

[10] Slavov, C., Donkov, I. and Popov, E. (2007) Case of Duplication of the Urethra in an Adult Male, Presenting with Symptoms of Bladder Outlet Obstruction. European Urology, 52, 1249-1251. http://dx.doi.org/10.1016/j.eururo.2007.01.019

[11] Das, S. and Brosman, S.A. (1977) Duplication of the Male Urethra. The Journal of Urology, 117, $452-454$.

[12] Woodhouse, C.R. and Williams, D.I. (1979) Duplication of the Lower Urinary Tract in Children. British Journal of Urology, 51, 481-487. http://dx.doi.org/10.1111/j.1464-410X.1979.tb03583.X

[13] Merrot, T., Weber, D., Steyeart, H. and Allessandrini, P. (2002) Sagittal Duplication of the Urethra in Children. Report of 7 Cases (Duplications sagittales de l'urètre chez l'enfant. À propos de sept observations). Progrès en Urologie, 12, 77-83.

[14] Jouini, R., Krichéne, I., Lefi, M., Chelly, S., Mekki, M., Belghith, M. and Nouri, A. (2003) Urethral Duplication in Male Childrens: Report of 4 Cases (La duplication urétrale chez le garçon: À propos de 4 cas). Annales d'Urologie, 37, 288-292. http://dx.doi.org/10.1016/S0003-4401(03)00039-1 